\title{
Three Themes for Designing Games that Aim to Promote a Positive Body Perception in Hospitalized Children
}

\author{
Ruth Sancho Huerga ${ }^{1}$, Jennifer Lade ${ }^{1}$, Florian 'Floyd' Mueller ${ }^{1}$ \\ ${ }^{1}$ Exertion Games Lab, RMIT University, Melbourne, Australia \\ $\{$ ruth, jennifer, floyd $\}$ @exertiongameslab.org
}

\begin{abstract}
Hospitalized children often experience physical changes that negatively affect their bodily perceptions, thereby adding to the stress of being sick. Existing approaches to supporting hospitalized children such as those promoted by the Clown Doctors use play to distract the child from negative bodily perceptions. In contrast, we propose reframing the bodily perception of these children through bodily virtual play facilitated by their imagination. We explore this design space through an analysis of the literature combined with design explorations around play and bodily imagination. This research results in a set of themes for games that aim to reframe bodily perception to a more positive self-image full of creative potential. We envisage that our work could help designers who aim to create digital play for sick children.
\end{abstract}

\section{Introduction}

Children's hospitals are increasingly introducing complementary care programs that facilitate play for sick children. However, we note that there has been little work in designing play projects that reframe body perception in hospitalized children. In this context our work utilizes digital and physical play to improve children's health. We propose a design space with a set of three themes that can be used as a guide for games designers when designing play that aims to reframe sick children's body perception.

Whilst conducting a review of the literature and engaging with the design process, we worked as a team that included academics, theatre and bodily expression experts, designers and computer programmers. We also engaged two children so far during the game design explorations.

In this paper we present an overview of current works and literature that are relevant for creating games for children in hospital. We present concepts relevant to creating games for health and discuss our approach when creating games for sick children focused on reframing bodily perception. 


\section{Related Work}

Over the last 20 years different therapeutic play works addressing body perception in sick children have been developed to be used as mental and physical complementary care in hospitals. Associated studies have found that this alternative non-medical treatment can help sick children through therapeutic play to enhance their coping, development and adaptation to life changes, supporting complementary care for mental and physical health [3]. For instance, organizations such as Clown Doctors [8] and Therapeutic Clowns [9] address the issue of body changes and body perception through clown improvisation. Clowns use props such as puppets, music and magic to help them approach and express feelings about their changing body perception in a safe, comfortable and creative environment. Studies assert that clowns performing with children requiring surgery can be effective for managing children's anxiety [10]. However, there are no studies articulating if and how such approaches can facilitate a positive body perception. We therefore see an opportunity to use a non-medical care method such as therapeutic play to support the body perception of sick children.

Children find digital technology a very familiar media [6] and engagement in this media allows them to explore their imagination [2]. We therefore also focus on the digital to explore imagination. Research previously suggested that combining digital media with physical objects could be used for physical recovery treatment [11]. For example "Elements" by Jonathan Duckworth et al. [11] is an interactive table top that supports rehabilitation of patients recovering from traumatic brain injury. Elements supports painting, creating music, matching objects and shapes by using physical objects in a digital environment to enrich the experience of recovery treatment. This inspired us to believe that physical objects could be useful for physical recovery treatment while at the same time a digital environment could create a playful platform to apply therapeutic exercises. The "Elements" system targets body perception in both areas, mental and physical health and facilitates imagination, however it is not addressed at sick children.

Digital objects have recently been designed to support complementary care within a therapy context. Magic Land [6] is an interactive table top that consists of four different toys implemented on a smart table to help children understand and overcome feelings of anxiety. The following games demonstrate how the system enables a wide range of different activities to support complementary care: "Flying Feathers" supports imagination, "Rosebush" supports play, "Hero/Avatar" supports fantasy playing and "Water" supports new play opportunities. This suggests to us that digital interactive play can support therapeutic play. However, Magic Land does not address to physical health so far.

In summary, we have presented a number of projects that target sick children while considering body perception. However, we find a gap when it comes to complementary care that aims to help children developing different body perception. We see an opportunity to explore this gap through the development of a design space and we focus on facilitating this through a set of themes for games that aim to reframe bodily perception. 


\section{Design Approach}

We used an examination of existing literature and design explorations to derive a design space for designers to create games that could reframe sick children's body perception. We identified three main themes for reframing body perception. These three themes were derived from analyzing papers selected from these domains: health, complementary care, games, children's psychology and body perception. We further refined these three themes by exploring designs around physical play, virtual play and bodily - virtual play.

Bodily Play. We created props such as puppets made out of medical gloves and puppets made out of x-rays of a child. During this development and associated play we noticed that the child was mirroring his puppet's movements and behaviors. He imagined he was a lion and started physically embodying the lions' power through his body, moving his arms and hands up and down as claws, roaring, attacking and feeling empowered [fig. 1]. The child reframed his bodily perception through bodily play transforming his body into a new one full of power.

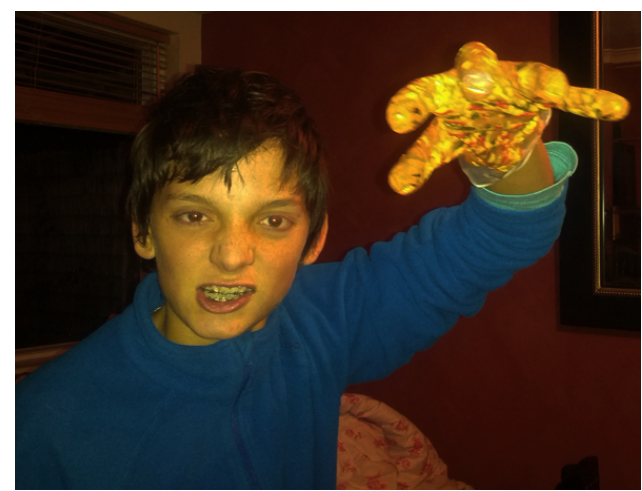

Fig. 1. Child mirroring the puppet's movements and behaviors

Virtual Play. We created "Laughter Tree", a Kinect game based on a laughter therapy activity [1]. We developed this game to explore bodily virtual play to reframe body perception. We designed a tree made of pictures of the children's arms and hands that drops leaves which laugh when the player grabs them via the avatar [fig.2]. The game has so far been played by seven adults and two children, who reported the game to be fun and engaging. 


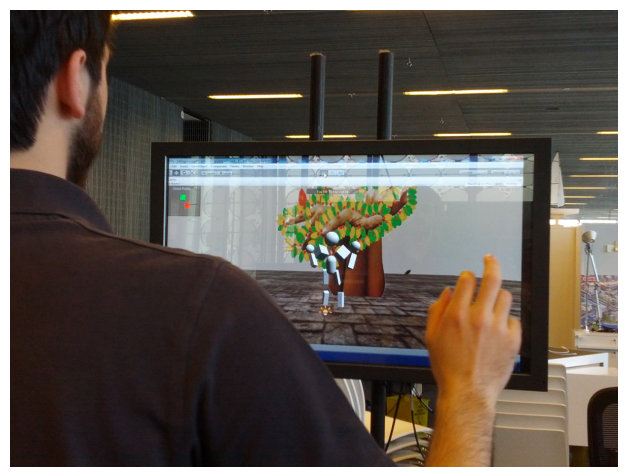

Fig. 2. "Laughter Tree": moving one's arm facilitates laughter triggered in the virtual world

Bodily - Virtual Play. Through our design explorations we were inspired to combine the two approaches, for example, we were interested in using the glove puppets in a digital environment, effectively using them as controllers [fig.3]. Using glove puppets as controllers could result in a combined physical and virtual system that facilitates engagement further [2].

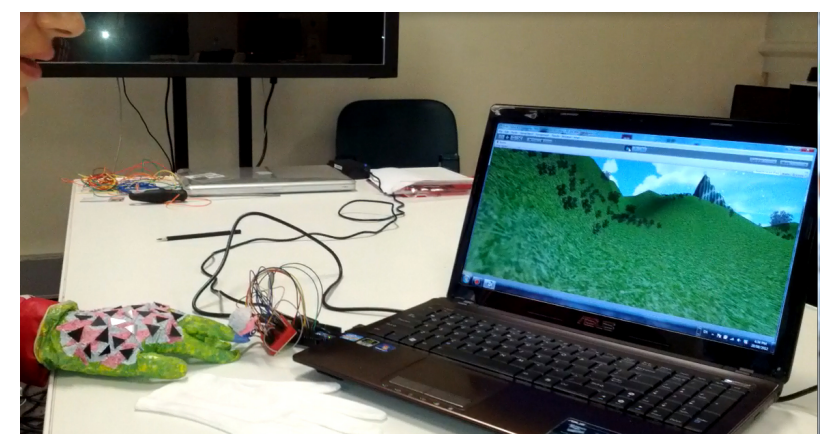

Fig. 3. Puppets made out of medical gloves to control virtual environments

\section{Design Space for Reframing Body Perception Through Bodily Virtual Play}

After reviewing the literature and analyzing the design explorations we came up with three main themes that we believe are a good start for designing the reframing of body perception through bodily virtual play.

\subsection{Empowerment of the body through bodily play}

Children in hospital environments can feel restricted, stressed and vulnerable [4]. We believe that setting a scenario where the child controls the situation and feels owner- 
ship of the environment can change this. We propose that through bodily play we can empower the child's perception of his/her body. Through bodily play the sick child may reframe her body perception while using it for an entertaining, positive and constructive purpose rather than addressing it only for medical reasons.

\subsection{Engagement of the body through the imagination facilitated by digital media.}

Children play because they have fun, enjoy, laugh and develop their imagination [5]. It is through the imagination that children can learn in the most constructive, positive and creative way [5]. The imagination is enriched by the use of digital media [3]. Through the development of Laughter Tree while using Jacques L'ecoq's 'outercourse' improvisation techniques [7] we found out that the child can imagine better ways of using her body when facilitated by the use of digital media. We believe facilitating engagement of the body through the imagination facilitated by digital play enhances the change from the perception of a sick body to a different one full of creative potential.

\subsection{Sociability through reframed body perception facilitated by digital media}

Hospitalized children can experience adverse side effects in their body due to medical treatment. These changes affect children's mental and physical body perception resulting in a decrease of children's desire to socialize [4]. Those children isolate themselves avoiding social contact that ends up in a deterioration of their mental and physical health. We believe that designing games that reframe the body perception can help sick children to empathize with other sick children and feel socially supported rather than isolated and lonely. During the design process we discovered that enabling multi-players functionality could not only contribute to engagement, but could also help sick children to socialize with other sick children.

\section{$5 \quad$ Discussion and Conclusion}

The design space and the three themes have yet to be confirmed. Although we have presented the games to adult participants and two children, we have not yet presented it to sick children. Our next step is to undertake a study with sick children in hospital to confirm the design space and the three themes.

In this paper we have presented our design explorations combined with an analysis of the literature resulting in the creation of a design space and a set of three themes for creating games that aim to reframe bodily perception. We anticipate that our work can help designers to use digital play for positive health change in sick children. 


\section{Acknowledgments}

We would like to thank Rhys Sullivan, Mathew Sullivan, Christopher Mackenzie, Yueyue Mo, Courtney Blackney, Leon Eduardo Diaz Jacobi and Arrulfo Diaz Trujillo for their collaboration.

\section{References}

1. Adams, R. E., McGuire, A. F.: Is Laughter the Best Medicine? A Study of the Effects of Humor on Perceived Pain and Affect. In: Activities, Adaptation and Aging, vol 8, pp. 157175 (1986)

2. Calvillo-Gamez, E. H., Cairns, P.: Pulling the Strings, A Theory of Puppetry for the Gaming Experience. In: Proc of the Philosophy of Computer Games, pp308-323. University Press, Potsdam (2008)

3. Koller, D. Gryski, C.: The Life Threatened Child and the Life Enhancing Clown: Towards a Model of Therapeutic Clowning. In: Evidence-Based Complementary and Alternative Medicine, vol 5, pp. 17-25 (2008)

4. Larouche, S. S., Chin-Peuckert, L.: Changes in Body Image Experienced by Adolescents with Cancer. In: Journal of Pediatric Oncology Nursing, vol 23, pp. 200-209, (2006)

5. Ott, M., Pozzi, F.: Digital games as creativity enablers for children. In: Behaviour \& Information Technology, vol 31, pp.1011 - 1019 (2012)

6. Pykhtina, O., Balaam, M., Wood, G., Pattison, S., Kharrufa, A., Olivier, P.: Magic Land: The Design and Evaluation of an Interactive Tabletop Supporting Therapeutic Play with Children. In: Proc of the Designing Interactive Systems Conference, pp. 136-145 (2012)

7. Sherman, J.F.: The Practice of Astonishment: Devising, Phenomenology, and Jacques Lecoq. In: Theatre Topics Journal, vol 20, pp. 89-99 (2010)

8. The Humour Foundation, Clown Doctors, http://www. humourfoundation. com. au/our-work/clowndoctors.html

9. The Canadian Association of Therapeutic Clowns, http: //www. therapeuticclowns.ca/

10. Vagnoli, L., Caprilli, S., Robiglio, A., Messeri, A.: Clown Doctors as a Treatment for Preoperative Anxiety in Children: A Randomized, Prospective Study. In: Pediatrics, vol 116, pp. 563-467 (2005)

11. Wilson, P., Duckworth, J., Munford, N., Eldridge,R., Guglielmetti, M., Thomas, P., Shum, D., Rudolph, H.: A Virtual tabletop workspace for the assessment of upper limb function in Traumatic Brain Injury (TBI). In: Proc of Virtual Rehabilitation, 2007, pp. 14-19. IEEE (2007) 